\title{
In Situ Profiling of Eastern Arabian Sea Coastal Waters Using a New Autonomous Vertical Profiler
}

\author{
Elgar de Sa, Member, IEEE, R. Madhan, Nitin Dabholkar, Shivanand Prabhudesai, Gajanan Navelkar, \\ Antonio Mascarenhas, Sanjeev Afzulpurkar, Mruga Phaldesai, and Pramod Kumar Maurya
}

\begin{abstract}
The autonomous vertical profiler (AVP) presented here offers a fast, cost-effective, optimized approach to profiling in coastal waters. It consists of a hands-free, slightly buoyant, motor-driven in situ robot profiler that requires no operator skill or deployment gear, but fulfills the requirements of repetitive profiling of the water column. It uses standard oceanographic sensors to measure vertical structure at high resolution $(\sim 10 \mathrm{~cm})$ in waters as shallow as $5 \mathrm{~m}$ and as deep as $200 \mathrm{~m}$. The detailed engineering design, hydrodynamics, safety systems, endurance, and performance of the AVP relative to other profilers are covered in this paper. Proof-of-concept experiments in coastal waters present a clear picture, for the first time, of stable interactions between constant density contours and chlorophyll maxima in the waters of the Coral Island of Kavaratti (in the Lakshadweep Archipelago). The AVP has also been used in deep dives to $200 \mathrm{~m}$ in shelf regions of the Arabian Sea to record the presence of anoxic layers and phytoplankton existing in low-oxygen conditions.
\end{abstract}

Index Terms-Coastal, processes, profilers, water column.

\section{INTRODUCTION}

$\mathbf{T}$ HE coastal zones of the world's oceans are home to nearly half the world's population living within $50 \mathrm{~km}$ of the coast and providing for most of its protein needs while contributing to a large portion of the global fish catch [1]. However, coastal areas are prone to extreme natural events as well as acting as a sink for pollutants generated by human-induced activities. There is a need to understand these ecosystems through systematic monitoring of processes, timely data access, and sustainable management of marine resources through well-informed decisions. The coastal module of the Global Ocean Observing System (GOOS) [2] notes that while meteorological and physical data collection is well advanced, ecosystem health is the least advanced and needs operational in situ monitoring of chemical and biological variables of ecosystems.

Manuscript received December 13, 2011; revised May 09, 2012; accepted July 11, 2012. Date of publication August 27, 2012; date of current version January 09,2013 . This work was supported by the Department of Information Technology, Ministry of Communications and Information Technology, New Delhi, India, under a Grant-in-aid project, and by the National Institute of Oceanography, Goa, India.

Associate Editor: J. Jaffe.

The authors are with the Marine Instrumentation Division, National Institute of Oceanography, Dona Paula, Goa 403 004, India (e-mail: elgar@nio.org; madhan@nio.org; ndabholkar@nio.org; shivanand@nio.org; navelkar@nio.org; antonio@nio.org; sanjeev@nio.org; phaldesaim@nio.org; maurya@nio.org).

Color versions of one or more of the figures in this paper are available online at http://ieeexplore.ieee.org.

Digital Object Identifier 10.1109/JOE.2012.2209234
In situ vertical structure profiling of the water column provides data on relevant ecosystem variables below the sea surface. In contrast, satellite-based sensors provide synoptic estimates of sea surface temperature (SST) and surface phytoplankton distributions over large 1-km-long swaths of the ocean surface from sensor payloads on orbiting satellites like Oceansat 2, SeaWiFs, and MODIS. When both technologies are used in combination, they provide complementary data sets for constructing local algorithms that can be ingested into coastal models for the predicted evolution of coastal processes. The dynamics of coastal ecosystems involves a close interaction between biological, physical, and chemical processes over small space scales $(<1 \mathrm{~km})$ and short time $(<12 \mathrm{~h})$ scales. The environmental monitoring of coastal processes using profiling technology has direct applications in studies on the impact on the environment by coastal industries, and the longer term consequences of climate change on coastal ecology.

\section{A. In Situ Profilers}

The conventional workhorse used widely by oceanographers in profiling the water column is the well-known rosette conductivity-temperature-depth (CTD) system which is lowered toward the seabed from a ship's winch. Portable CTD logging instruments are now available for use from small boats but these are hand lowered, slow, and labor intensive if several profiles are required quickly. Optical and chemical sensors on these manual systems are affected by the close proximity to the ship/boat hull, the effect of ship shadow, or by pitch and roll perturbations superimposed on the package motion. Other types of free-falling profilers, e.g., HyperOCR (SatlanticInc, Halifax, NS, Canada), are prone to tilt errors caused by surface waves, density stratification, or cable drag and buoyancy effects (T. Suresh, personal communication). The Autonomous Profiling Explorer/Autonomous Lagrangian Circulation Explorer (ALACE/APEX) array of profiling floats has been specifically designed for open-ocean descents to $2000 \mathrm{~m}$ with a lifetime of about 400 cycles. The design emphasis has been directed toward the use of CTD sensors, although that is now changing to accommodate BIO-ARGO floats carrying ecosystem-relevant sensors of chlorophyll, light attenuation, and backscattering for biogeochemical/bio-optical studies in the open ocean [3]-[5]. Each cycle of the float takes between 6 and $10 \mathrm{~h}$ to execute with the float descending at very low speeds of the order centimeters per second.t Therefore, open-ocean floats are unsuitable for shallow coastal waters where rapid profiling of dynamic processes is necessary to capture quick changes in the water-column structure. Portable winch-operated profilers have been developed for estuarine applications, but these are 
cumbersome and outdated systems [6]. An interesting profiler development is the wire-guided walker that uses ocean wave energy to drive a buoyant instrumented platform down a wire from a surface float at profile speeds between 0.17 and $0.33 \mathrm{~m} / \mathrm{s}$, and when ascending to the surface at a quicker rate of $0.5 \mathrm{~m} / \mathrm{s}$. A cam that rectifies vertical motion is released when the wire walker hits a mechanical stop after which the wire walker floats to the surface [7]. More recent developments have been reported on small shallow-water buoyancy-driven Lagrangian floats profiling at speeds of $0.33 \mathrm{~m} / \mathrm{s}$, but with settling times of the order of tens of seconds and operating within a selected range of seawater densities [8]. However, buoyancy-driven systems can be optimized for specific depth ranges but will suffer in speed in shallow-water dives or may not have sufficient power in deep-water applications. The autonomous thruster-actuated air-sea interaction profiler (ASIP) and the submerging controller addition SUCA are recent experimental profilers targeted for research on air-sea interfacial and near-surface processes in the 10-m surface layer. The ASIP is $2 \mathrm{~m}$ in length and weighs $100 \mathrm{~kg}$, and would be very difficult to operate as a profiler for routine use from a boat in shallow coastal waters without a deployment gear [9], [10]. For completeness, we include the class of towed profilers, namely, the moving vessel profiler (MVP), and the SeaSoar that carries sensor packs for data acquisition. The MVP is a ship-based system that uses a computer-controlled smart winch and deployment system that allows a free-fall fish to be deployed while the vessel is underway. It was originally designed to acquire sound-speed data for hydrographic operations (www.brooke-ocean.com). The SeaSoar is a towed undulating batfish for deep-water measurements from dedicated research vessels. It is capable of undulating from the surface to $500 \mathrm{~m}$ at tow speeds of up to $12 \mathrm{kn}$ (with faired cable) following a controlled and adjustable undulating path through the ocean (www.chelsea.co.uk). Both systems are expensive and need special purpose winch systems, cables, and an operator to control and receive real-time data.

In this paper, we describe the design and development of a small robot profiler-the autonomous vertical profiler (AVP) - that can be launched quickly by a single person from a research vessel or a trawler. It is substantially different in function and performance from all known developments in profilers reviewed above. The concept of a thruster-driven profiler was first proposed by the authors in a U.S. Patent \#6786087 [11]. The design and performance tests on the AVP are described below and proof of concept is presented by time-series field experiments in the Coral Islands of the Lakshadweep Archipelago, and deep-water dives in the shelf waters off Goa, India, in the southeastern Arabian Sea. The scientific results reveal the influence of density gradients on the distribution of phytoplankton in the water column, and the presence of anoxic waters and phytoplankton existing in low-oxygen conditions.

\section{DESIGN OF THE AVP}

The principle of operation of the AVP involves a dynamic balance between the motor thrust $T$ that propels the AVP in the assumed "positive is downwards" direction against the sum of onboard buoyancy force $B$ (with contributions from the foam module and hull volume) and drag force $D$ on the AVP, both

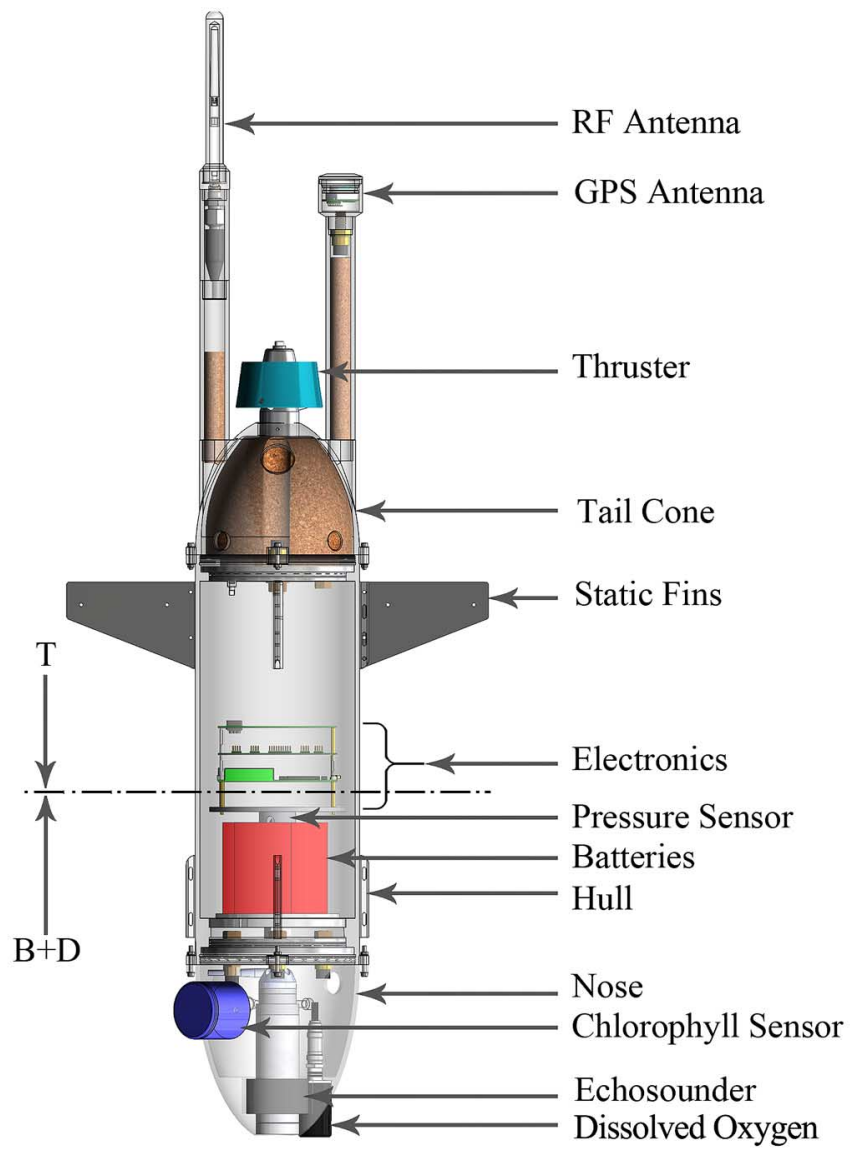

Fig. 1. Three-dimensional drawing of the AVP with its nose oriented downwards as would be the case before a dive. Thrust $T$, buoyancy $B$, and drag force $D$ and their directions are marked on the drawing. Length from nose tip to thruster shroud is $0.86 \mathrm{~m}$. (See Table I for other dimensions). The echo sounder is located on the vertex of the nose cone.

acting upwards to the sea surface. This balance is expressed as $T=[B+D]$. When the motor is powered down $(T=0)$, drag force $D$ and buoyancy $B$ act in opposite directions, i.e., $-B=+D$. The AVP ascends with buoyancy to the sea surface and floats vertically on the surface with antenna stubs protruding above the water line. When $T=B$, the AVP can be made to hover in a quasi-stationary state at a constant depth (the hover control system will be addressed in a separate communication).

\section{A. Physical Design}

An annotated 3-D computer-aided design (CAD) of the AVP in Fig. 1 shows its nose oriented downwards as would be the case before a dive. The device consists of three parts, namely: 1) the nose cone; 2) the main hull (or mid-body section) with sealed plates at either end; and 3) the tail cone. The ellipsoidal nose cone was prototyped from Acetal SA550 grade cylinder to house an echo sounder for seabed detection, and sensors of chlorophyll, turbidity, and dissolved oxygen. The main cylindrical hull was machined to 6-mm wall thickness from an extruded section of aluminum alloy tube to house the electronics and the batteries. The hull is sealed at both ends with double O-ring grooved 6061 aluminum alloy removable plates kept in place by retainer rings threaded on the internal flange of the 


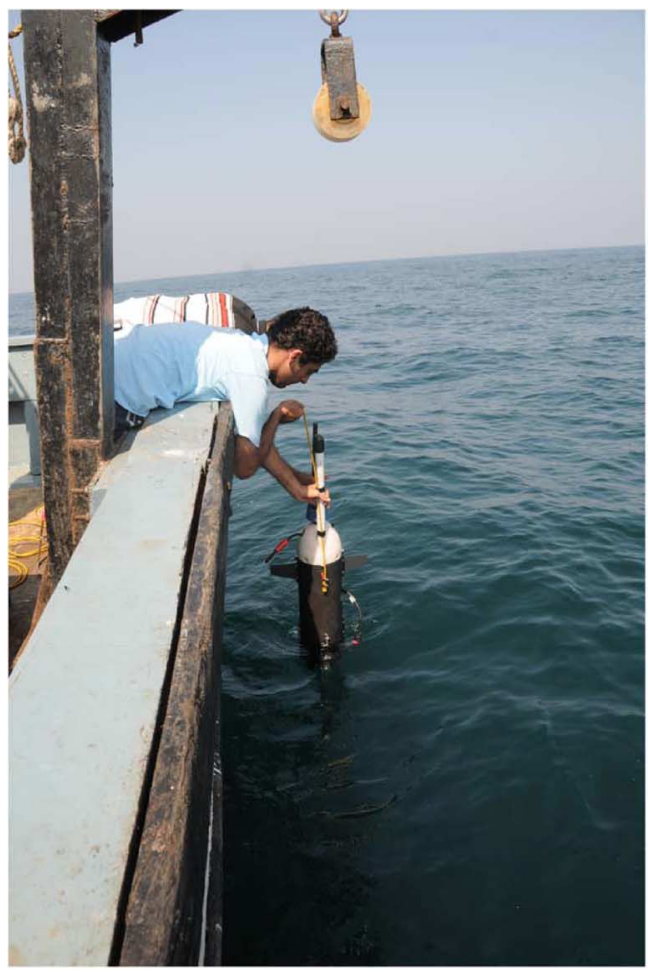

(a)

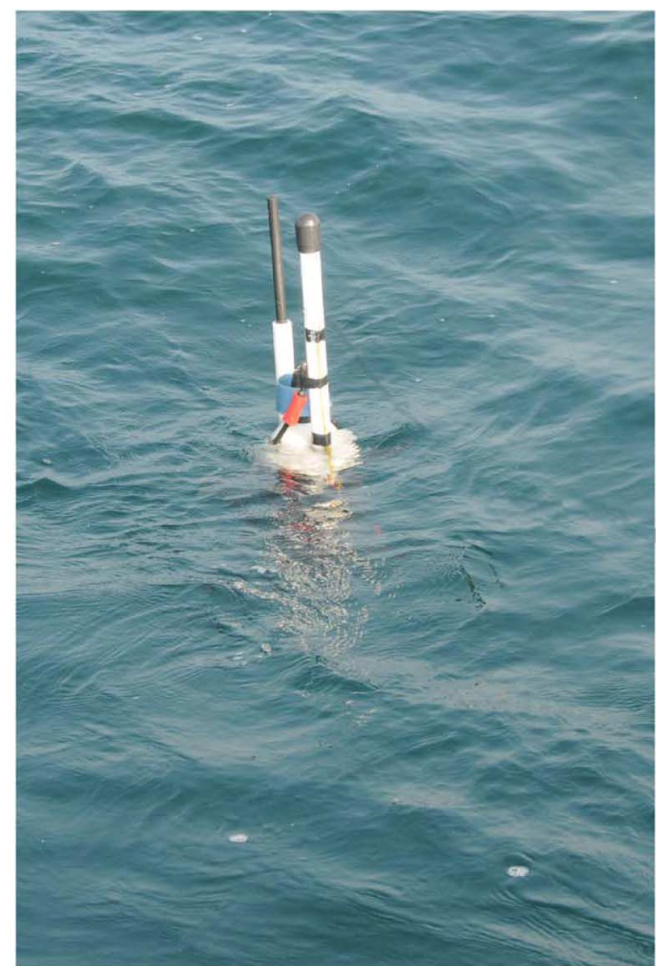

(b)

Fig. 2. (a) Profiler being deployed from the ship with a 6-mm nylon rope as tether. (b) Profiler floating unassisted in water ready for a dive command over the RF link.

hull wall. The end plate at the nose end has five machined ports for underwater sensor connectors including a pressure sensor whose sensing port is located at its center. The tail cone (similar in shape to the nose cone and also made from Acetal) is free flooding and serves the purpose of accommodating a conical foam module, a locking collar to hold the thruster body securely, and exit holes for the thruster nozzle and blades, Global Positioning System (GPS), radio frequency (RF), or satellite modem antenna stubs to emerge above the water line. The end plate at the tail end has five O-ringed connector inserts for all the above, including a connector for charging the batteries externally. The nose and tail cones fit over machined overhangs on the hull wall and are secured with small nuts and bolts to form a single rigid body. Eight external ribs are machined out from the original hull wall for mounting fixed fins to inhibit rotation of the AVP when in motion, or to carry additional sensors payloads like the CTD and acoustic tag.

\section{B. Operation of the AVP in the Field}

The AVP orients vertically on the sea surface by ensuring through design a large enough separation between the centers of buoyancy and gravity. It carries wet sensors and an echo sounder on its nose cone and is propelled from the rear by a brushless underwater motor run at a selected constant speed. As it nears the programmed depth, the motor thrust is smoothly ramped down to zero, bringing the AVP to a halt close to the desired depth layer above the sea bed. At the end of a dive, the AVP automatically ascends to the surface in the same orientation at the rate of $\sim 0.3 \mathrm{~m} / \mathrm{s}$ with fixed onboard buoyancy of $\sim 350 \mathrm{~g}$. On reaching the sea surface, the AVP transmits time-stamped sensor profiles and its GPS coordinates over a high-speed RF modem
(2.4 GHz, $115 \mathrm{kbaud}$ ) to a user in a nearby ship. A user-friendly Graphical User Interface (GUI) on the user's notebook is linked to the AVP, and is used to check its system health and sensor values and to configure a mission for single or for multiple unsupervised dives. Sensor data are updated and displayed every $5 \mathrm{~s}$ with appropriate warnings on the notebook. After a dive is completed, all sensor data are download and stored as a file on a notebook. The main page on the GUI is used as a blackboard to view downloaded annotated sensor profiles, or to mark the GPS coordinates of the AVP and its distance from the user location.

During field operations, the AVP is deployed or retrieved from the aft of the vessel using a thin nylon rope securely fixed to the external ribs on the hull. The nylon rope is kept loose enough so as to decouple the AVP from vessel movements during a dive. If the tether is removed, the AVP will drift and execute dives at programmed intervals as before, but now as a fully autonomous platform. The inherent buoyancy is of practical use during deployment at sea, as it enables the user to see the AVP float away from the proximity of the ship. In contrast, negatively buoyant instrument packages also sink away but are out of sight after being deployed in the water. When it is sufficiently distant from the ship/trawler, the mission script is downloaded over the RF link to the electronics of the AVP and a command is transmitted to start the dive(s). A low-cost acoustic tag can be attached to an external rib on the AVP hull to help locate its position at sea in case it is lost at sea.

\section{Performance Characteristics of the AVP}

In this section, we describe several design aspects of the AVP which were addressed during its development phase, and which ultimately shaped its specifications (as in Table I). In particular, 
TABLE I

MAIN SPECIFICATIONS OF AVP

\begin{tabular}{|c|c|}
\hline \multicolumn{2}{|c|}{ Autonomous Vertical Profiler Specifications } \\
\hline $\begin{array}{l}\text { Alloy Hull Dimensions } \\
\text { Length \& Diameter }\end{array}$ & $\mathrm{L}=1.17 \mathrm{~m} ;$ Diameter $=0.184 \mathrm{~m}$ \\
\hline Weight in air & $\sim 13 \mathrm{~kg}$ (depending on sensors weight) \\
\hline Nose and Rear Cones & $\begin{array}{l}\text { Removable Acetal ( Science sensors on Nose } \\
\text { Cone ) }\end{array}$ \\
\hline Tested Depth & $200 \mathrm{~m}$ \\
\hline Propulsion & $\begin{array}{l}\text { Model } 260 \text { Tecnadyne } 24 \text { VDC Brushless } \\
\text { motor, max }-5 \mathrm{kgf} \\
\text { forward thrust, max depth } 750 \mathrm{~m}\end{array}$ \\
\hline Nominal specd & $0.4 \mathrm{~m} / \mathrm{s}$. (Max specd $1 \mathrm{~m} / \mathrm{s})$ \\
\hline Endurance (estimated) & 7 days with 4 dives/day to $100 \mathrm{~m}$ \\
\hline Power source & Lithium Ion Polymer cells ( $324 \mathrm{Wh}$ ) \\
\hline Total average power & $60 \mathrm{~W}$ max (includes thruster \& payloads ) \\
\hline $\begin{array}{l}\text { Electronics } \\
\text { GUI }\end{array}$ & $\begin{array}{l}\text { Microcontrollers - } 8051 \text { and two ARM7 as CAN } \\
\text { nodes } \\
\text { Labview ( National Instruments) }\end{array}$ \\
\hline Communications & $\begin{array}{l}2.4 \mathrm{GHz}, 115 \mathrm{kbaud} / \text { Satellite Iridium modem } \\
\text { (optional) }\end{array}$ \\
\hline Vehicle Payloads: & Pressure sensor, GPS , Echo-sounder \\
\hline Science sensors : & $\begin{array}{l}\text { Chlorophyll, Turbidity, CTD (Conductivity- } \\
\text { Temperature-Depth), Dissolved Oxygen }\end{array}$ \\
\hline
\end{tabular}

we examine: 1) hydrostatics; 2) drag profile; 3 ) minimizing momentum overshoot beyond the programmed depth; 4) power and endurance of the vehicle; and 5) specifications of AVP.

\section{A. Hydrostatics}

Our first concern when designing the AVP was to ensure that its long axis was oriented perpendicular to the sea surface before the start of a dive. A reasonable vertical separation between the $\mathrm{CG}$ and $\mathrm{CB}$ coordinates was obtained by placing the batteries and sensors toward the nose cone, and by incorporating a conical foam plug within the rear cone near the motor (as in Fig. 1). Calculations using standard drawing packages estimate the vertical $Z$-axis separation between the $\mathrm{CG}$ and $\mathrm{CB}$ coordinates to be $\left[Z_{\mathrm{CG}}-Z_{\mathrm{CB}}\right] \sim 56.65 \mathrm{~mm}$ with $\mathrm{CB}$ located above the CG. The restoring hydrostatic moment is then given by $M_{\mathrm{HS}}=W \theta g\left[Z_{\mathrm{CG}}-Z_{\mathrm{CB}}\right]$, where $W$ and $\theta$ represent the weight and the tilt angle (in degrees) of the AVP from the vertical direction, respectively. For a typical weight $W=13 \mathrm{~kg}$ and a $1^{\circ}$ change, the restoring moment is $7.21 \mathrm{Nm}$. At an increased weight of $W=16 \mathrm{~kg}, M_{\mathrm{HS}}$ will increase to $8.87 \mathrm{Nm}$. The CG calculations of the AVP components were used to compute the principal moments of inertia referenced to the $X-, Y$-, $Z$-axes at the CG as $I x x=I y y=3.14 \mathrm{~kg} \cdot \mathrm{m}^{2}$ and $I z z=$ $0.0054 \mathrm{~kg} \cdot \mathrm{m}^{2}$. The low value of $I z z$ explains the momentum overshoot of the AVP beyond the programmed halt depth after the motor is switched off as discussed below. The AVP can also undershoot if the motor is turned off too early during its descent dive.

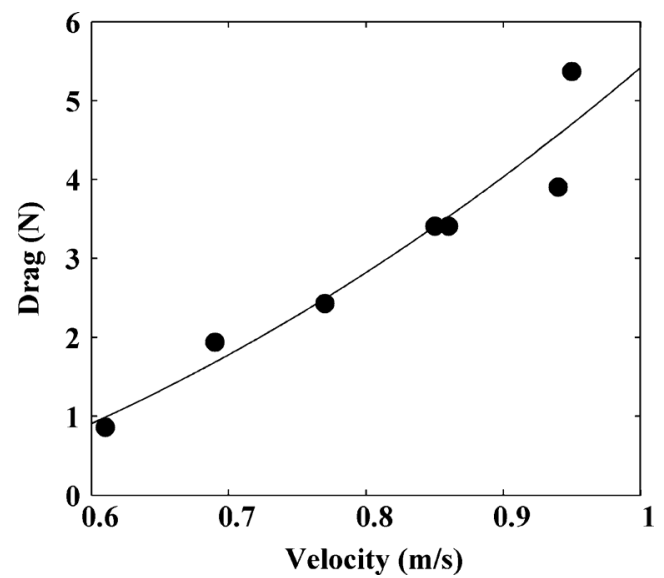

Fig. 3. Experimental drag force $(\mathrm{N})$ plotted as a function of AVP velocity $(\mathrm{m} / \mathrm{s})$ obtained from dives in a dam reservoir.

\section{B. Experimental Drag Profile of AVP}

The drag force $D=0.5 A_{f} C_{d} \rho U^{2}$ acting on the AVP was determined as a function of velocity $U$, without the need to perform measurements at a special purpose calibrated facility [12]. In this relation, $A_{f}$ is the frontal area of the hull, $C_{d}$ is the drag coefficient, and $\rho$ is the density of water. The following steps were taken in finding the drag.

1) Motor thrust $T$ [in kilogram-force (kgf)] was measured at different control voltages with a calibrated strain gauge cell in a water tank.

2) Experimental dives of the untethered AVP were carried out at the Amthane water reservoir in Goa, India, by energizing the thruster with a stepped ramp function until constant velocity was attained.

3) During the dives of 2), data from the pressure sensor on the AVP was sampled at $10 \mathrm{~Hz}$ and stored. The time response was differentiated and filtered to give the velocity profile. Steady-state velocity $U$ of the profile is used in the computations.

4) The balance of forces at constant velocity gives the drag force $D=\left[T-B_{\text {net }}\right]$, where $B_{\text {net }}$ is the known net buoyancy of $\sim 350 \mathrm{~g}(3.43 \mathrm{~N})$.

The drag force $D$ is plotted as a function of velocity in Fig. 3 . At an operating speed $U \sim 0.7 \mathrm{~m} / \mathrm{s}$, the drag experienced by the AVP is $\sim 1.57 \mathrm{~N}$ (160 gf), the drag coefficient $C_{d}=$ 0.23 , and the towing power $=\left(D+B_{\text {net }}\right) \times U=T \times U=$ $3.46 \mathrm{~W}$. The thruster delivers an input power of $34.8 \mathrm{~W}$ at $24 \mathrm{~V}$ and $1.45 \mathrm{~A}$, resulting in a propulsion efficiency of $\sim 10 \%$. At a speed of $0.95 \mathrm{~m} / \mathrm{s}$, the efficiency increases to $\sim 15 \%$. These efficiency values, although low, are acceptable for short-duration single-day trips. However, for long-duration measurements over several days, higher propulsion efficiency is needed and can be achieved by selecting (or customizing) thrusters that match mechanical thrust to electrical input power. Most propelled vehicles like autonomous underwater vehicles (AUVs) are designed to be positively buoyant, and propulsion efficiencies from $\sim 30 \%$ to $40 \%$ are common [13]. 


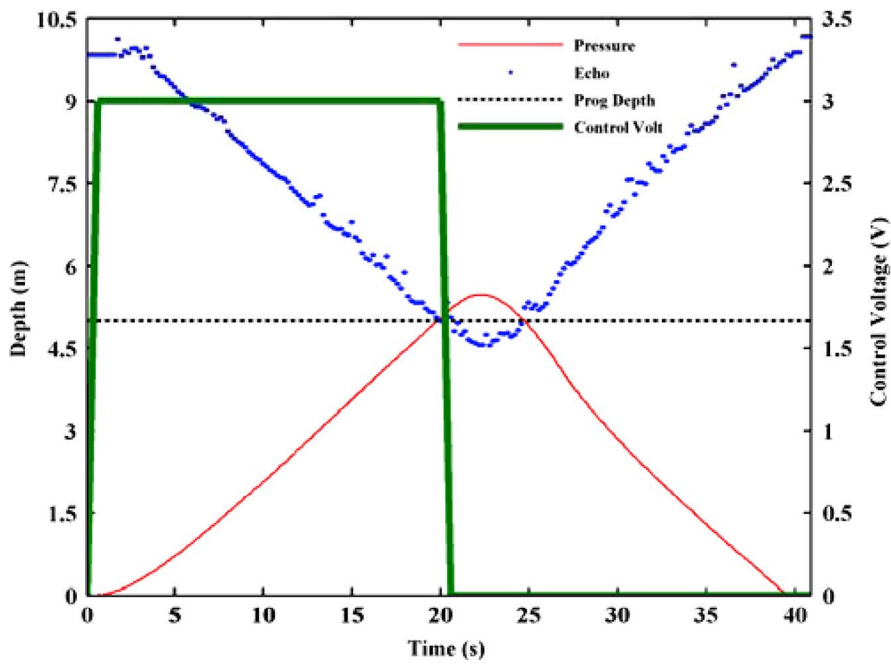

Fig. 4. Overshoot of AVP is shown by the turning point on the thin trace going past the programmed depth $(\mathrm{PD}=5 \mathrm{~m})$. The dotted trace is formed by the echo returns which gives the distance from seabed as the AVP approaches it. The step function in bold shows the thruster control voltage being ramped up to $3 \mathrm{~V}$ and then ramped down to $0 \mathrm{~V}$.

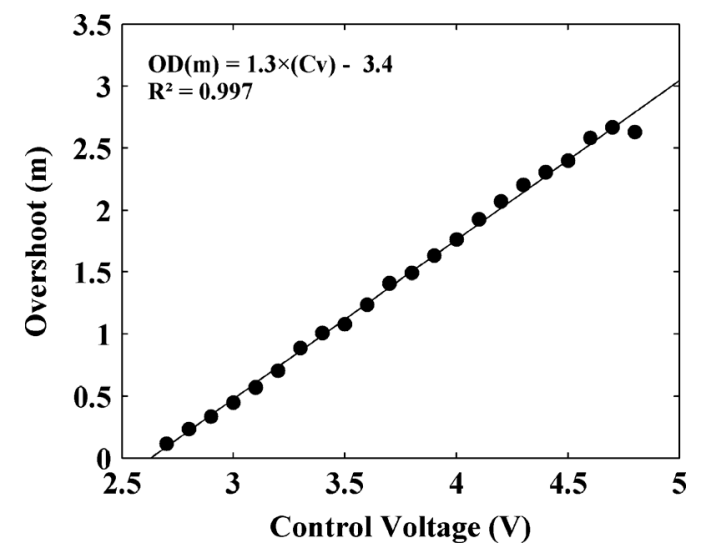

Fig. 5. Experimental linear variation of OD with thruster $\mathrm{Cv}$. This is used to know when to ramp down the motor control voltage so that the overshoot is minimized.

\section{Minimizing Momentum Overshoot of the AVP}

The tendency of the AVP to continue moving past the userprogrammed depth (PD), even after power to the thruster is cut off, is due to the momentum imparted to it by the motor thrust. As no extra insight on data is gained by a precise stop, we relaxed the conditions on attaining exact $\mathrm{PD}$, and define the overshoot distance (OD) as the extra distance covered by the AVP beyond what was programmed by the user (PD), as in Fig. 4.

OD was found, by an experiment, to depend on several factors, e.g., the motor thrust set by the control voltage, which in turn decides the speed of the AVP, the drag force on it, and the net buoyancy. An empirical approach was used to determine OD at different step control volts $(\mathrm{Cv})$ applied to the motor by doing experimental dives of an untethered AVP in a water reservoir. The results of these measurements for a fixed PD give the best fit linear equation $(\mathrm{OD}=1.3 \times \mathrm{Cv}-3.4)$, shown in Fig. 5. The equation was built into the software code of the AVP and used to find the difference in the depths (PD-OD) as a cue to when to ramp down the power to the motor at a rate of $0.5 \mathrm{~V} / 100 \mathrm{~ms}$ so

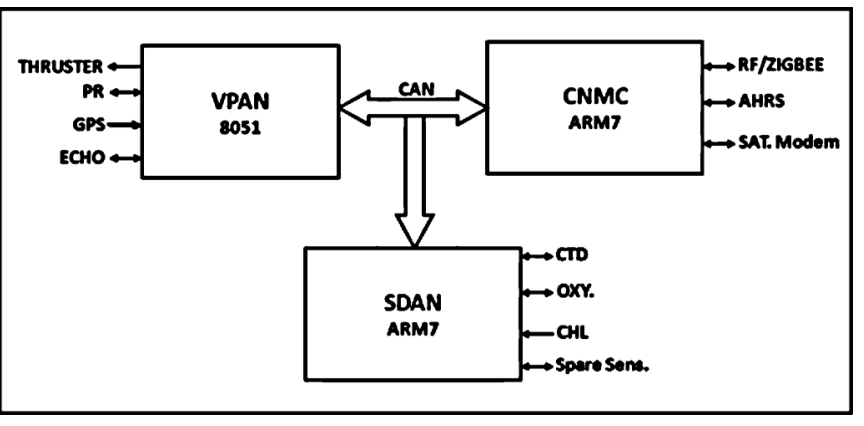

Fig. 6. The AVP electronics uses a distributed control architecture to share data acquisition and control tasks over a CAN.

that the overshoot distance was minimized but not completely annulled.

\section{Endurance of the Vehicle-Payloads and Propulsion}

Two dedicated battery packs are used to supply direct current (dc) power to the sensor payloads and the thruster motor on the AVP, respectively. The payloads consist of sensors of chlorophyll, CTD, dissolved oxygen (DO), pressure sensor, digital echo sounder, GPS, RF/satellite modems, and electronics present a load of $\sim 8.22 \mathrm{~W}$, while the thruster motor consumes $35 \mathrm{~W}$ in typical operations. To arrive at the realistic estimate for the endurance of the AVP, we assume the following conditions:

1) four dives in a day with each dive to $100 \mathrm{~m}$;

2) typical dive speed at a constant $0.4 \mathrm{~m} / \mathrm{s}$;

3) all sensors are powered up during a dive except for the $\mathrm{RF} /$ satellite modems;

4) AVP ascends without the thruster power, but all payloads are still powered;

5) at the surface, sensors are switched off, but GPS and RF modems are switched on;

6) during data transmission, the modems, GPS, and part of the electronics are powered up.

Given these conditions, the endurance of the AVP is estimated to be $\sim 7$ days. Longer endurance up to a month is possible by using high-efficiency thrusters, a higher $A h$ rating of the battery banks, and low-power embedded controllers.

\section{E. Distributed Electronics on the AVP}

The distributed electronic architecture of the AVP is based on two Phillips LPC2368 ARM7 processors, namely, communication navigation and mission controller (CNMC), science data acquisition node (SDAN), and a Silicon Laboratory C8051F041 vehicle parameter acquisition node (VPAN) communicating internally over a controller area network (CAN) interface, as shown in Fig. 6.

VPAN executes commands and acquires, and monitors data from vehicle payloads, namely, the thruster motor, GPS, echo sounder, the pressure sensor, and the internal battery modules. The CNMC node, besides executing the mission program and other tasks, handles the RF communications between GUI on the user laptop and the AVP. The function of SDAN is to initialize, acquire, store, and transmit over the CAN network all science data acquired from DO, CTD, chlorophyll-a, and turbidity sensor to the CNMC. 
TABLE II

SCIENCE SENSORS INTERFACED TO THE SCIENCE NODE SDAN ON THE AVP

\begin{tabular}{|c|c|c|c|}
\hline Sensor & $\begin{array}{l}\text { Range \& } \\
\text { Accuracy }\end{array}$ & Sampling & Response \\
\hline $\begin{array}{l}\text { Dissolved } \\
\text { Oxygen }\end{array}$ & $\begin{array}{c}0-200 \% \mathrm{DO}(\mu \mathrm{M}) \\
\text { Linear } \pm 2 \% \mathrm{FS}\end{array}$ & $\begin{array}{l}1 \mathrm{~s} \text { to } 255 \mathrm{~min} . \\
1 \mathrm{~Hz} \text { in AVP }\end{array}$ & $\sim 1 \mathrm{~s}$ \\
\hline Chlorophyll & $0.02-60 \mu \mathrm{g} / \mathrm{l}$ & \multirow{2}{*}{$\begin{array}{l}\sim 8 \mathrm{~Hz} \\
(4 \mathrm{~Hz} \text { in } \\
\text { AVP) }\end{array}$} & $<125 \mathrm{~ms}$ \\
\hline Turbidity & $0-25 \mathrm{NTU}$ & & $<125 \mathrm{~ms}$ \\
\hline Conductivity & $\begin{array}{c}0 \text { to } 90 \mathrm{mS} / \mathrm{cm} \\
( \pm 0.002 \mathrm{mS} / \mathrm{cm})\end{array}$ & \multirow{3}{*}{$\begin{array}{c}\sim 8 \mathrm{~Hz} \\
(4 \mathrm{~Hz} \text { in } \\
\text { AVP) }\end{array}$} & $<95 \mathrm{~ms}$ \\
\hline Temperature & $\begin{array}{c}n-5^{\circ} \mathrm{C} \text { to } 45^{\circ} \mathrm{C} \\
\left( \pm 0.005^{\circ} \mathrm{C}\right) \text { (Accu) }\end{array}$ & & $100 \mathrm{~ms}$ \\
\hline Depth & $\begin{array}{l}0 \text { to } 740 \mathrm{dBars} \\
(<0.08 \% \mathrm{FS})\end{array}$ & & $25 \mathrm{~ms}$ \\
\hline
\end{tabular}

The design of the software routines on the AVP incorporates safety checks specific to the AVP function but necessary in all the autonomous propelled vehicles.

- Control voltage to the thruster is checked to prevent thruster turning on accidentally.

- The thruster is ramped up in steps of $0.5 \mathrm{~V} / 100 \mathrm{~ms}$ until the AVP attains constant speed.

- The thruster is turned off should the AVP cross the maximum pressure depth or the echo-sounder altitude above the seabed be less than the preset value (e.g., $\sim 2$ or $3 \mathrm{~m}$ ).

- A mission is initiated only when all system checks are cleared over the RF link.

- On arriving at the sea surface, the CNMC node on the AVP activates the RF modem and transmits the latest sensor file on the serial digital (SD) card with time- and depthstamped values of the last dive profile. The data streams are received on the laptop GUI and stored immediately for safety.

\section{F. Sensors, Sampling Rates, and In Situ Comparisons}

1) Sensors: The specifications of sensors connected to the science node of the AVP are listed in Table II, showing range, accuracy, and the maximum sampling rate. The sensors include an active fluorometer (EcoPuck Wetlabs, St. Philomath, OR) that measures chlorophyll and turbidity, a fast DO sensor (RINKO III, Nishi-ku, Kobe, Japan), and CTD (FSI, Cataumet, MA). The vehicle sensors are listed separately in Table I and these include a pressure sensor, an echo sounder, GPS, and an RF modem. Most of the science sensors including the pressure sensor are located within the nose cone (see Fig. 1). The CTD, due to its larger size, was secured to the side ribs of the AVP near the nose cone.

2) Sampling Rates of Sensors: The sampling rates of the pressure sensor, CTD, fluorometer, and DO sensors are 10, 8, 4 , and $1 \mathrm{~Hz}$, respectively. Given that the resolution of a sensor variable is equal to (speed of AVP)/(sampling rate), a judicious choice under present sensor limitations was to run the profiler

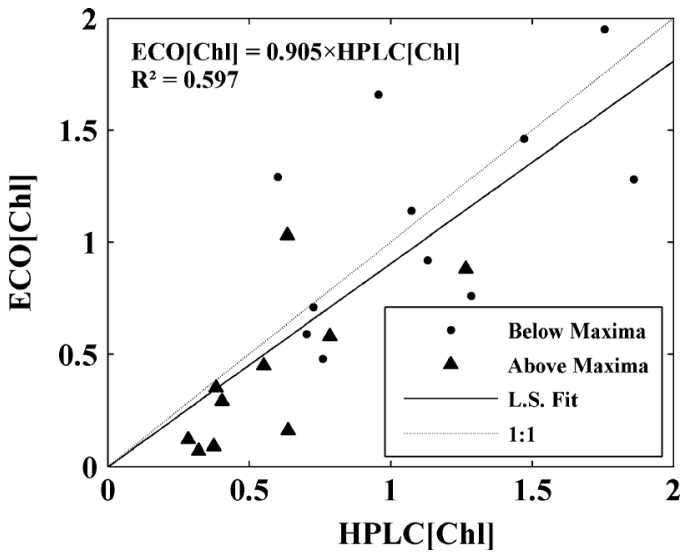

Fig. 7. In situ calibration plot compares independent measurements from fluorometer sensor (in $\mathrm{mg} / \mathrm{m}^{3}$ ) and the HPLC estimate of extracted chlorophyll from water samples extracted from depths where dives were made during April 13, 2010 and May 10, 2010 at coastal locations only. Samples removed from below and above the chlorophyll maxima are drawn as solid circles and triangles, respectively. The solid line is a least squares fit, and the dashed line is the ideal $1: 1$ line.

at an operational speed of $0.4 \mathrm{~m} / \mathrm{s}$, and to sample the pressure sensor at $10 \mathrm{~Hz}$, and the CTD and fluorometer each at $4 \mathrm{~Hz}$. This gives a $4-\mathrm{cm}$ resolution in depth values, and $10-\mathrm{cm}$ resolution for the CTD and fluorometer sensors. The DO sensor at $1 \mathrm{~Hz}$ offers profiles at $40-\mathrm{cm}$ resolution, the best possible until faster response sensors are available. To achieve, say, higher resolution of $5 \mathrm{~cm}$ at a speed of $0.4 \mathrm{~m} / \mathrm{s}$ would require all sensors to be able to operate at $8 \mathrm{~Hz}$, which currently are not commercially available.

\section{G. In Situ Calibration of Sensors}

1) Fluorometer: Chlorophyll molecules in phytoplankton emit red fluorescence (of $685 \mathrm{~nm}$ ) when blue light (of 430 $\mathrm{nm}$ ) from the fluorometer irradiates a sample of water close to its face. In general, one expects that the intensity of red fluorescence would increase nonlinearly with an increase in concentration of chlorophyll. Water samples for the estimation of chlorophyll were collected using AVP dive profiles to help pin point the best depths for water collection. All the 24 data points were obtained in coastal waters of the Arabian Sea at locations where depths varied between 30 and $40 \mathrm{~m}$, and at times from late morning to early afternoon in April and May 2010. The chlorophyll-a concentration (in $\mathrm{mg} / \mathrm{m}^{3}$ ) in the extracted samples, as determined by the high-performance liquid chromatography (HPLC) analysis against the AVP fluorometer chlorophyll, is shown in Fig. 7. The root mean square deviation (RMSD) between the in situ chlorophyll (from EcoPuck sensor) relative to the HPLC values is $39 \%$ for the data set used. The cause for the large observed fluorescence variability is not surprising, and can be attributed to ambient changes in sunlight affecting fluorescence output, dark count drift of the fluorometer, photo-inhibition, nutritional status, the time of day, species composition, accessory pigments, colored dissolved organic matter, and turbidity from particles in suspension in the water column [14]. Clearly, this requires a separate study, far beyond the scope of this paper. Proctor and Roesler [15] have studied these aspects comprehensively and have been able to 


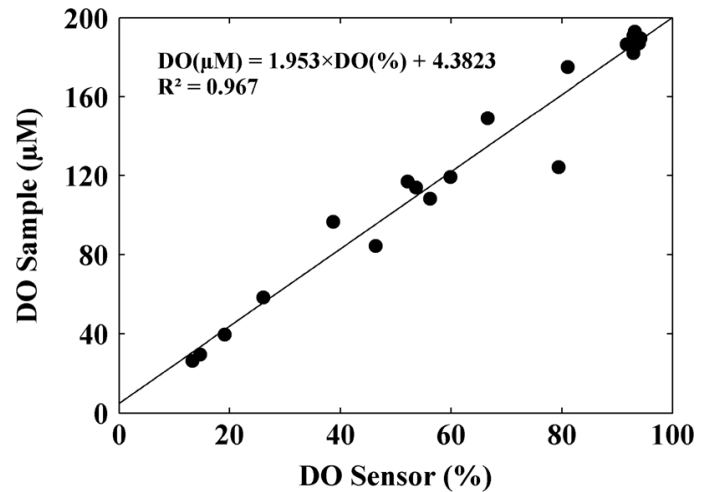

Fig. 8. In situ calibration plot compares the DO sensor output (percent saturation) with the DO $(\mu \mathrm{M})$ measured from water samples by the Winkler titration method at the same ship location.

reduce errors in estimating in situ chlorophyll-a from $>30 \%$ to $<6 \%$.

2) DO Sensor: The calibration method used here is similar to the in situ approach used in estimating fluorometric chlorophyll. The RINKO sensor produces a temperature and DO output both as analog signals. These signals are digitized and empirical algorithms supplied by the manufacturer to correct the DO output for temperature and depth changes in the water column. The final DO sensor output is computed in units of percent saturation. Water samples were collected at two shallow-water stations off Goa (west coast of India) and the concentration of DO (in $\mu \mathrm{M}$ ) determined by the standard Winkler titration technique. This was plotted versus the DO sensor output (in percent saturation) as in Fig. 8. The linearity of the sensor is $\pm 2 \% \mathrm{FS}$ and the DO range of $0 \%-200 \%$ is well covered by the data points. This calibration-conversion equation was used to express the DO sensor (from percent saturation to $\mu \mathrm{M}$ ) for the 200-m profile by the AVP (in Fig. 14). The independent measurements of DO $(\mu \mathrm{M})$ from water samples (shown as solid circles) are plotted versus the corresponding DO sensor output in percent saturation derived from depths selected from the AVP profiles-showing excellent linearity with a high correlation coefficient of 0.967 .

\section{H. Comparison of the Shapes of AVP Profiles With the Ship's CTD System}

To be certain, we have compared the temperature and chlorophyll profiles from the AVP with the corresponding variables measured by Seabird CTD system on the ship (see Fig. 9) taken on the same day and about the same time during a cruise to the Arabian Sea on April 28, 2009. The offset between the ship and depth profiles is caused by calibration differences in the different depth sensors used on the two systems. What is important here is the similarity in the shapes of both profiles over the full water-column depth to $50 \mathrm{~m}$.

\section{EXPERIMENTAL RESULTS}

We describe two experiments that were carried out at different locations in the Arabian Sea coastal waters, both from ships and trawlers (Fig. 10). The rationale for doing this not only demonstrates proof of concept of the AVP, but also shows that useful scientific data can be acquired by the method of time-series profiling of high-resolution structure to capture the dynamics of the

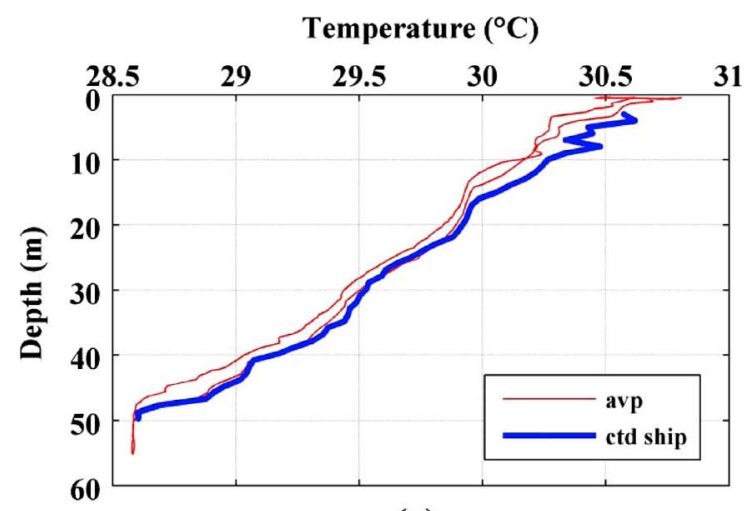

(a)

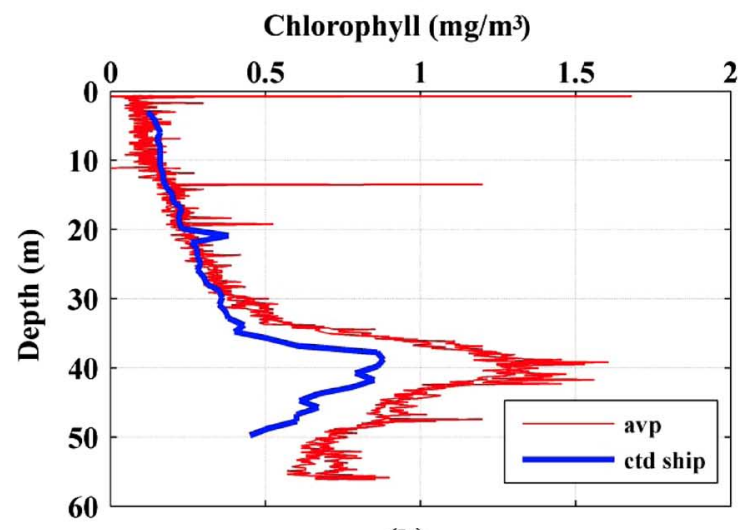

(b)

Fig. 9. Qualitative comparison in the shapes of profiles measured by the AVP and sensors on a ship's CTD system for the (a) temperature and (b) chlorophyll-a.

coastal processes. As discussed below, this has provided, for the first time, a clear picture of the interaction between biological, physical, and chemical processes.

\section{A. Time-Series Profiling in Waters Near Kavaratti Island, Lakshadweep (India) - November 2009}

The AVP was deployed during a short cruise in November 2009 to Kavaratti Island $\left(\sim 4.22 \mathrm{~km}^{2}\right)$ adjoining the Lakshadweep Archipelago of the south eastern Arabian Sea. The month of November falls in the post-monsoon period when the salinity lens (i.e., a low-saline fresh water surface layer from the monsoon rains floats over cold high-saline water) thins out [16]. Kavaratti Island is surrounded by a large lagoon (of the $4.96-\mathrm{km}^{2}$ area) connected to the open ocean. The sky was clear with scant clouds; the lagoon surface was calm, bluish green in color with low measured turbidity $[\sim<0.1$ nephelometric turbidity unit (NTU)]. The water depth at this location was $1070 \mathrm{~m}$, and therefore, the ship was subjected to drift as it could not be anchored. The AVP profiling began at 11:20:00L on November 18, 2009 and continued every $\sim 2$-h intervals over a 24-h period until the next morning, resulting in 14 dives to $\sim 45 \mathrm{~m}$. Due to strong currents acting on the ship, it was necessary to haul in the AVP after each dive, and deploy it $2 \mathrm{~h}$ later. A south-western drift less than $1.8 \mathrm{~km}$ was periodically corrected by maintaining the ship close to reference coordinates latitude $10^{\circ} 36^{\prime} 45^{\prime \prime} \mathrm{N}$ and longitude $72^{\circ} 17^{\prime} 15^{\prime \prime} \mathrm{E}$ during the experiment. The oceanic water body was stable and homogeneous over this spatial spread of the drift area. A typical dive 


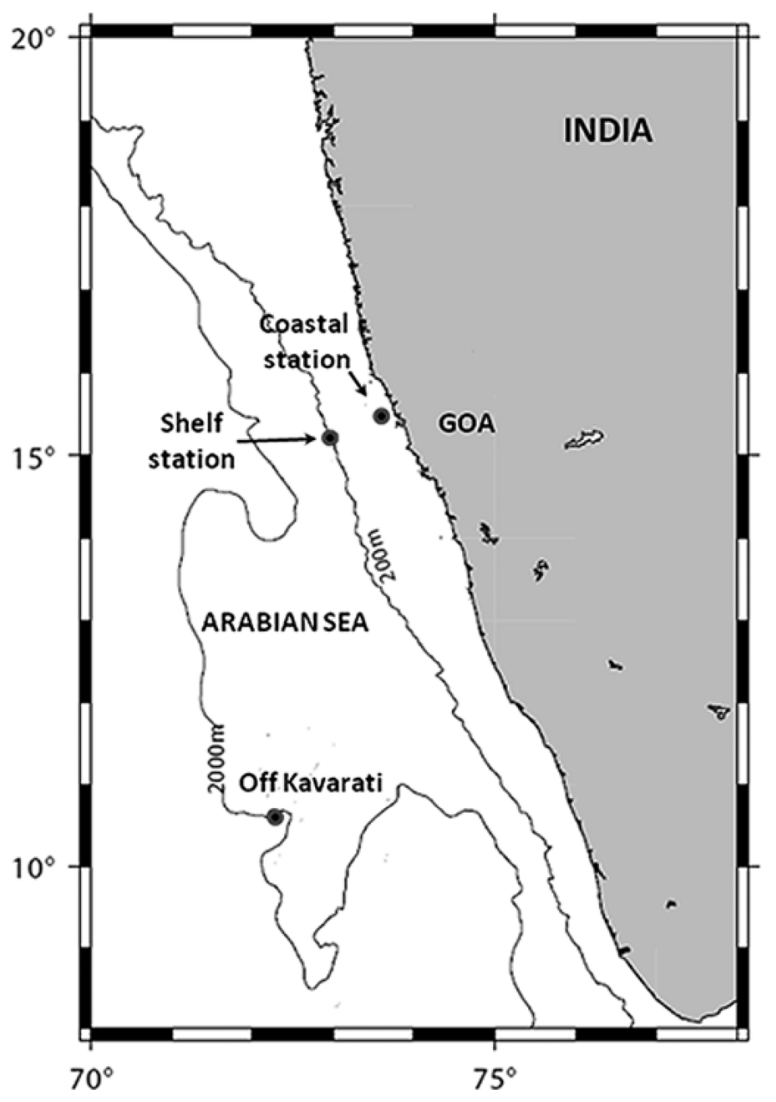

Fig. 10. Location coordinates of Kavaratti Island (Lakshadweep Archipelago) on 2000-m contour, the shelf area on the 200-m contour, and the two coastal sites $(30-40 \mathrm{~m})$ where the AVP has been tested on various occasions. All stations are off the west coast of India in the Arabian Sea.

set consists of high-resolution vertical profiles of chlorophyll (Chl-a), turbidity, temperature $(T)$, and salinity $(S)$, measured concurrently in a single AVP transect, as shown in Fig. 11.

The density profile for each dive was derived from the corresponding $T-S$ profiles using the UNESCO algorithms [17]. When a set of 14 profiles are merged and interpolated using the Surfer ${ }^{\mathrm{TM}}$ Software, a clearer picture of time-series interaction between density gradients and chlorophyll distributions is revealed. The deep chlorophyll maximum (DCM) tends to aggregate and maintain stability on the 23.5 density contour (Fig. 12). It also explains our initial puzzlement over why the DCM appeared to sink to $40 \mathrm{~m}$, then rise to about $35 \mathrm{~m}$ in late evening, remain at this depth until midnight, before sinking down again to beyond $45 \mathrm{~m}$, and rising again by sunrise. The oscillatory shape of the 23.5 density contour with time would explain this observation.

The satellite penetration depth at $470 \mathrm{~nm}$ was spectrally measured independently (A. Mascarenhas, personal communication) to be $16.5 \mathrm{~m}$ and is marked in Fig. 12 to show that satellite ocean color sensors will fail to detect significant phytoplankton distribution in deeper layers below the surface of the ocean.

Yentsch [18] first suggested the idea that the time and space distribution of phytoplankton was largely dictated by the steepness of the isopycnal and its contribution to vertical mixing of nutrients into the euphotic zone. Subsequently, Cullen [14]

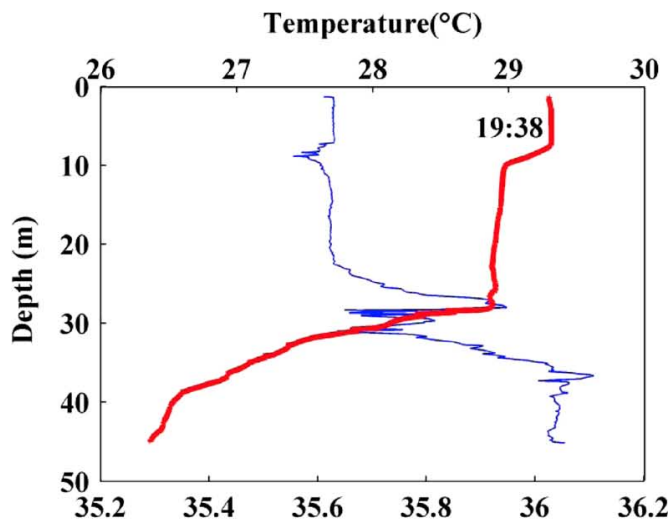

(a)

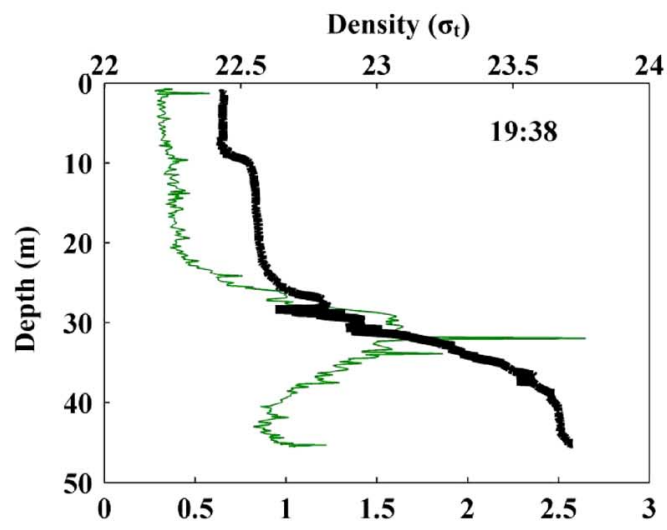

(b)

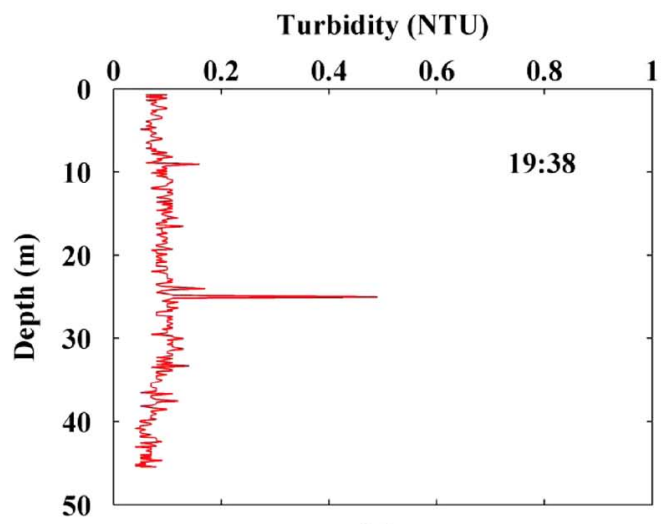

(c)

Fig. 11. Concurrent high-resolution profiles of (a) salinity (PSU) (thin line), temperature (bold line); (b) chlorophyll-a $\left(\mathrm{mg} / \mathrm{m}^{3}\right)$ (thin line) and density (bold line); and (c) turbidity, all taken at 19:38:00L on November 18, 2009 during a single dive in Kavaratti waters. The $\sigma_{t}$ density profile is derived from the temperature-salinity $(T-S)$ profiles and is drawn into Fig. 11(b).

described different processes that determine the vertical structure in different environments. In particular, the typical tropical structure (TTS) was described as having a stable coupling between physical and biological processes and that the vertical profiles of chlorophyll have a well-defined relationship with the density gradients and thermal structure of the water column. Adopting this line of thought, we quantified the variation of the mixed layer depth (MLD) with the depth of the DCM and found them to be well correlated as in Fig. 13. Interestingly, some point pairs (MLD-DCM) at higher depth values on this graph were obtained from AVP profiles during a revisit cruise to 


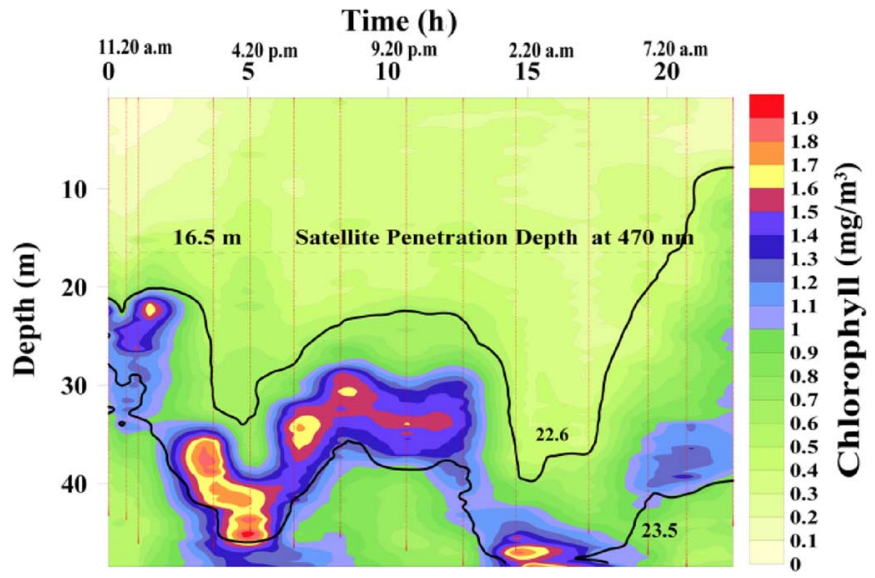

Fig. 12. Contours of the evolution of chlorophyll-a concentration and constant density surfaces (black) obtained by the time-series profiling. These were obtained by merging 14 time-series profiles of temperature $(T)$, salinity $(S)$, chlorophyll of AVP dives (shown as vertical dashed lines) over 24-h period at a deep-water station off Kavaratti Island (Lakshadweep Archipelago).

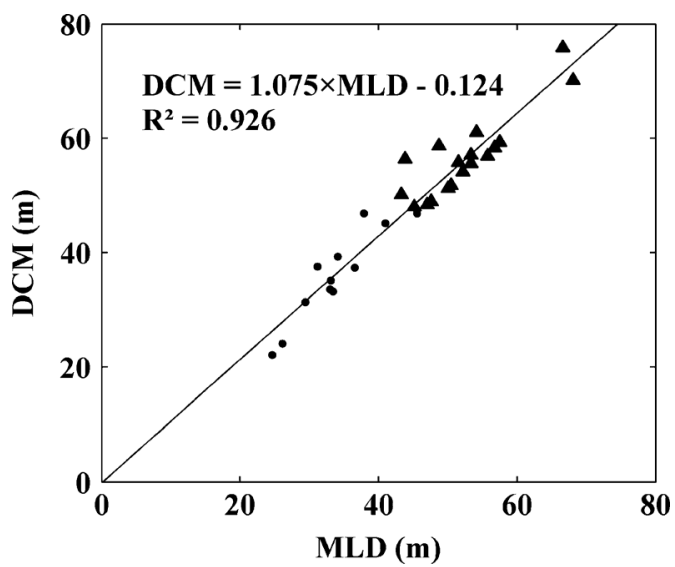

Fig. 13. Linear variation of DCM with MLD measured during two Lakshadweep cruises: SASU 199 (November 2009, solid circles) and five months later in SASU 191 (March 2010, solid triangles) at approximately similar latitude/longitude coordinates.

the same Kavaratti Islands location five months later, in March 2010, during the spring inter-Monsoon season.

\section{B. AVP Profiles From the Shelf of the East Arabian Sea (December 2010)}

The second experiment is a further example of the operational capability of the AVP to deeper depths in the shelf waters of the Arabian Sea. In this demonstration, the AVP dived close to its maximum designed depth of $200 \mathrm{~m}$, showing that it can be used in diverse environments encountered in the coastal zone.

We detected a stable, long-lasting shelf profile of DO and chlorophyll taken with the AVP during the SSK 009 Cruise on December 12, 2010. The profile features were also seen before and after December 12,2010, during a transect along the shelf (see the map in Fig. 10 and the profile in Fig. 14). The chlorophyll maximum (DCM) is located very near the DO knee and the base of the first density gradient; a second density gradient (not shown) coincides with the small but detectable DO maximum at $120 \mathrm{~m}$. A closer look at the chlorophyll profile of Fig. 14 shows that nearly half of the phytoplankton population lives in

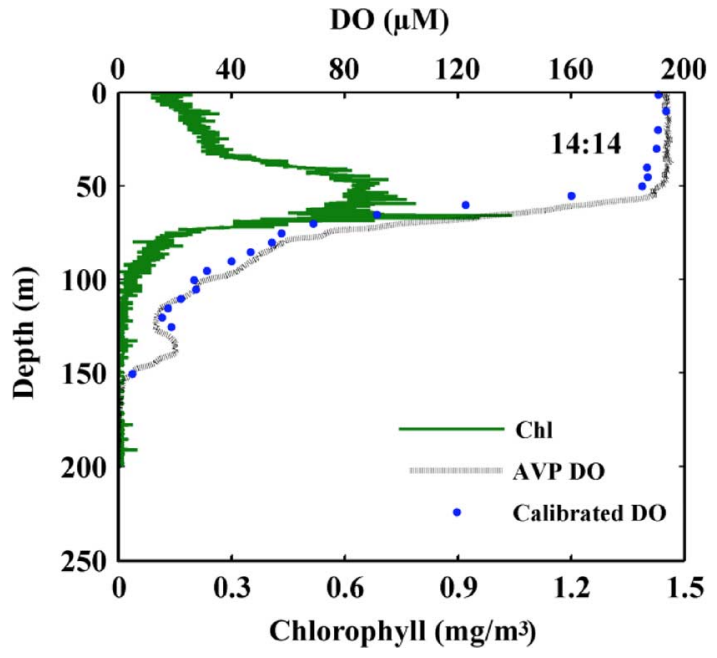

Fig. 14. Profile of DO (dashed gray line), chlorophyll fluorescence (thin line), and DO measured from water samples (solid circles) during 200-m dives by the AVP in the shelf waters of east Arabian Sea off Goa, India.

high DO $(\sim 200 \mu \mathrm{M})$ waters between 0 and $50 \mathrm{~m}$ - the euphotic depth where the light level was measured to be $1 \%$ surface PAR (measured by T. Suresh, personal communication), while the other half of the phytoplankton population exists in rapidly depleting DO values of $200 \mu \mathrm{M}$ at $50 \mathrm{~m}$ to anoxic values of $<5 \mu \mathrm{M}$ at $150 \mathrm{~m}$ with a concurrent depletion of the chlorophyll concentration to zero by $\sim 120 \mathrm{~m}$. The detection of anoxia at depths of $140 \mathrm{~m}$ and at locations well before the shelf break is unexpected. The effect could be due to the shoaling of the thermocline on to the shelf transporting perennial oxygen minimum zone (OMZ) waters [19] from beyond the central Arabian Sea. The low irradiance light and the sizeable chlorophyll concentration $\sim 0.7 \mathrm{mg} / \mathrm{m}^{3}$ suggest the possibility of photo acclimation [20], but more data on nitrate levels would be required to arrive at definite conclusions.

\section{DISCUSSION}

The method of in situ profiling of coastal waters using the thruster-driven AVP offers several practical and innovative advantages to conventional ways of profiling. For example, a hand lowered portable CTD having a typical weight of $30 \mathrm{~kg}$ with lead collar would take up to $5 \mathrm{~min}$ to profile to a depth of $30 \mathrm{~m}$. In comparison, an AVP dive to the same depth will take $<1 \mathrm{~min}$ at a speed of $0.6 \mathrm{~m} / \mathrm{s}$. The shallow-water buoyancy float (SWBF) described earlier [8] and the AVP belong to the class of autonomous shallow-water profilers, and therefore, merit a detailed comparison. Consider the following performance characteristics of the SWBF.

1) The SWBF with a maximum profiling speed of $0.3 \mathrm{~m} / \mathrm{s}$ is slow for most coastal applications, e.g., a single transect to $200 \mathrm{~m}$ will take $\sim 11 \mathrm{~min}$. The AVP running at $0.6 \mathrm{~m} / \mathrm{s}$ will take half the time to $200 \mathrm{~m}$.

2) The autoballasting technique of the SWBF has a settling time to steady-state depth of the order of tens of seconds- too slow for most applications.

3) The SWBF needs energy to sink and even more energy against hydrostatic forces when ascending. 
4) In turbid coastal waters or in bloom dominated waters, it is clear that living plankton cells, suspended submillimeter detrital particles, will be drawn into the actuation chamber that may cause the SWBF pump to foul up even if a filter is used.

5) The SWBF actuated volume needs to be tuned to operate over a range of expected seawater densities in coastal waters and to the total weight of the payload it has to carry including an emergency drop weight.

6) Buoyancy effects from residual air bubbles in the volume changer, and in pockets of compressed air tubules inside the O-ring seals of end caps are problems that can influence performance at greater depths.

The drawbacks of the SWBF are obviated in the thrusterdriven AVP, as it is designed to work at higher profiling speeds in the range $0.4-0.95 \mathrm{~m} / \mathrm{s}$, with fast settling time $<2 \mathrm{~s}$, using a simple overshoot algorithm. The AVP saves power by using its motor only for descent dives but requires no power to ascend, as it is positively buoyant. It is not affected by density gradients in coastal waters, and works equally well in turbid and saline waters of the coast. It can be deployed easily by hand from a research ship, an inflatable craft, or a country trawler without any support gear.

Three versions of the AVP can be configured for the following applications.

1) A low-cost tethered AVP carrying chlorophyll-a, temperature, and photosynthetic available radiation (PAR) sensors operated on fishing trawlers qualifies as an appropriate technology that would benefit the community of marine scientists in developing countries. In situ data from this version can be assimilated into coastal models that use satellite data from ocean color, SST sensors, and geographical information systems (GISs) [21], [22].

2) A time-series version of the AVP was described in the first experiment of this paper. This can be deployed from an anchored rig or trawler and programmed to do multiple dives at set intervals through the day and night. This has applications in environmental monitoring of key coastal variables, and in oceanographic research that tracks the birth and decay of coastal phytoplankton blooms as a function of time [23].

3) A third version (not tested) is a long-endurance, deepdiving autonomous untethered Lagrangian drifting AVP with a satellite transceiver for transmitting GPS-tagged profiles to the shore laboratory. This is similar in most details to what has been presented here with minor alterations in software for interfacing to commercial satellite modems. A high-efficiency thruster, low-power electronics, and extra battery packs would be needed to increase endurance of the vehicle.

\section{CONCLUSION}

We have presented a detailed description of a recently patented profiler-the AVP. The description has covered the engineering design, hydrodynamics, performance characteristics, sensor calibration, safety, and comparison with a ship's CTD system. A short review of other profiling systems was included in the introduction. Proof of concept was demonstrated in two selected experiments where time-series profiling of the AVP was able to accurately track the biophysical interactions of phytoplankton populations with density contours in the waters of the Lakshadweep Islands in the eastern Arabian Sea. A second test of the AVP performance in the shelf waters of the Arabian Sea presented deep dives to $200 \mathrm{~m}$ close to its maximum depth rating, where it uncovered the existence of phytoplankton species living in low-oxygen layers. The special characteristics of the AVP include a choice of profiling speeds, high-resolution profiles, operation in near-shore depths of 5-200 $\mathrm{m}$ on the shelf edge of most coastal zones, and also in freshwater reservoirs with small trims in buoyancy. This places the technology in a niche area that encompasses the operation in all types of water bodies.

The endurance of the AVP in time-series profiling over extended periods is a drawback that is being addressed. Battery power can be conserved during and between dives, through the use of low-power microcontrollers and switching regulators in sleep mode, powering down sensor payloads and communications modems, and high-efficiency thrusters. These approaches are being tested to target month-long time-series deployments.

A simple innovation on the AVP that is currently being tested is the inclusion of a control system that balances the motor thrust to its resident buoyancy so as to hover the device at any desired altitude above the seabed. These new functions, with minor changes in software code on the AVP and the addition of a digital camera, will extend its usefulness to the area of vision and control in imaging coral reefs.

\section{ACKNOWLEDGMENT}

The authors would like to thank I. K. Sharma of DIT, New Delhi, India, for his support, encouragement and his full faith in their capabilities. They would also like to thank the Director of the National Institute of Oceanography (NIO, Goa, India) for having extended the use of Laboratory facilities; T. Suresh for advice; and N. Kakodkar, A. Dubey, and Project Assistants who have worked tirelessly to collect data in all weather conditions. This paper is Contribution 5201 from the National Institute of Oceanography, Goa, India - a constituent laboratory of the Council of Scientific \& Industrial Research (CSIR).

\section{REFERENCES}

[1] H. Lindeboom, "The Coastal Zone: An ecosystem under pressure," in Oceans 2020: Science, Trends and the Challenge of Sustainability. Washington, DC: Island Press, 2002, ch. 3.

[2] UNESCO, "An implementation, strategy for the coastal module of the global ocean observing system GOOS Rep. 148, IOC Information Documents Series 1217, 2005.

[3] J. K. B. Bishop, R. E. Davis, and J. T. Sherman, "Robotic observations of dust storm enhancement of carbon biomass in the North Pacific," Science, vol. 298, pp. 817-821, 2002.

[4] S. C. Riser and K. S. Johnson, "Net production of oxygen in the subtropical ocean," Nature, vol. 451, pp. 323-326, 2008.

[5] H. Claustre, J. Bishop, E. Boss, S. Bernard, J.-F. Berthon, C. Coatanoan, K. Johnson, A. Lotiker, O. Ulloa, M. J. Perry, F. D'ortenzio, O. Hembise, F. D'Andon, and J. Uitz, "Bio-optical profiling floats as new observational tools for biogeochemical and ecosystem studies: Potential synergies with ocean color remote sensing," in Proc. Oceans Observing Conf., Venice, Italy, Sep. 21, 2009, DOI: 10.5270/OceanObs09.

[6] J. V. Reynolds-Fleming, J. G. Fleming, and R. A. Luettich, "Portable autonomous vertical profiler for estuarine applications," Estuaries, vol. 25 , no. 1, pp. 142-147, 2002. 
[7] R. Pinkel, M. A. Goldin, J. A. Smith, O. M. Sun, A. A. Aja, M. N. Bui, and T. Hughen, "The wirewalker: A vertically profiling instrument carrier powered by ocean waves," J. Atmos. Ocean. Technol., vol. 28, pp. 426-435, 2010.

[8] A. Schwithal and C. Roman, "Development of a new Lagrangian float for studying coastal marine ecosystems," in Proc. IEEE OCEANS-Europe Conf., 2009, DOI: 10.1109/OCEANSE.2009.5278296.

[9] C. L. Stevens, P. Hill, M. J. Smith, and S. Popinet, "SUCA: An engine for repetitive autonomous profiling near the ocean surface," Limnol. Oceanogr., Methods, vol. 3, pp. 300-307, 2005.

[10] B. Ward and T. Fristedt, "Air-sea interaction profiler: Autonomous upper ocean measurements," in Proc. IEEE US/EU Baltic Int. Symp., 2008, DOI: 10.1109/BALTIC.2008.4625494.

[11] E. Desa, A. Pascoal, E. Desa, P. Mehra, R. Madhan, and G. P. Naik, "A controlled thruster driven profiler for coastal waters," U.S. Patent 6786087, Sep. 7, 2004.

[12] A. Abkowitz, "Stability and motion control of ocean vehicles," Massachusetts Inst. Technol. (MIT), Cambridge, MA, Sea Grant Project GH-1, 1969

[13] C. Silvestre and A. Pascoal, "Control of an AUV in the vertical and horizontal planes: System design and tests at sea," Trans. Inst. Meas. Control, vol. 19, no. 3, pp. 126-138, 1997.

[14] J. J. Cullen, "The deep chlorophyll maximum: Comparing vertical profiles of Chlorophyll," Can. J. Fish. Aquat. Res., vol. 39, pp. 791-803, 1982.

[15] C. W. Proctor and C. S. Roesler, "New insights on obtaining phytoplankton concentration and composition from in-situ multispectral Chlorophyll fluorescence," Limnol. Oceanogr., Methods, vol. 8, pp. 695-708, 2010.

[16] S. W. A. Naqvi, J. W. Moffet, M. U. Gauns, P. V. Narvekar, A. K. Pratihary, H. Naik, D. M. Shenoy, D. A. Jayakumar, T. J. Goepfert, P. K. Patra, A. Al-Azri, and S. I. Ahmed, "The Arabian Sea as a highnutrient, low chlorophyll region during the late Southwest Monsoon," Biogeosciences, vol. 7, pp. 2091-2100, 2010.

[17] UNESCO, "Algorithms for computation of fundamental properties of seawater," Rep. UNESCO/SCOR/ICES/IAPSO WG 51, Unesco Tech. Papers in Marine Science, 1983.

[18] C. S. Yentsch, Phytoplankton Growth in the Sea: A Coalescence of Disciplines: Primary Productivity in the Sea, P. G. Falkowski, Ed. New York: Plenum, 1980, pp. 17-32.

[19] S. W. A. Naqvi, D. A. Jayakumar, P. V. Narvekar, H. Naik, V. V. S. S. Sarma, W. D'Souza, S. Joseph, and M. D. George, "Increased marine production of $\mathrm{N} 2 \mathrm{O}$ due to intensifying anoxia on the Indian Continental Shelf," Nature, vol. 408, no. 16, pp. 346-349, 2000.

[20] K. Fennel and E. Boss, "Subsurface maxima of phytoplankton and chlorophyll: Steady-State solutions from a simple model," Limnol. Oceanogr., vol. 48, no. 4, pp. 1521-1534, 2003.

[21] S. Sathyendranath, "ChloroGIN: Use of satellite and in situ data in support of ecosystem-based management of marine resources," in Proc. Oceans Observing Conf., Venice, Italy, Sep. 21, 2009, DOI: 10.5270/ OceanObs09.

[22] E. Desa, R. Madhan, G. Navelkar, N. Dabholkar, A. Mascarenhas, S. Prabhudesai, E. Desa, S. Nayak, P. Maurya, A. Pascoal, K. Rajan, E. Urban, M. D. Fortes, and M. Kyewalyanga, "Autonomous platforms for studies in the coastal zone," in Proc. Oceans Observing Conf., Venice, Italy, Sep. 21, 2009, Additional Contribution No. ac4a08.

[23] M. Estrada and E. Berdalet, "Phytoplankton in a turbulent world," $S c i$ entia Marina, vol. 61, pp. 125-140, 1997.

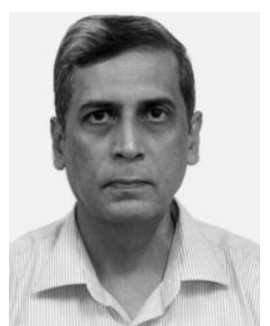

Elgar de Sa (M'07) was born in Kolkata, India. He received the B.Sc. and Ph.D. degrees in physics from the King's College, University of London, London, U.K., in 1973 and 1976, respectively.

Currently, he is Chief Scientist at the Marine Instrumentation Division, National Institute of Oceanography, Goa, India. He has, to his credit, patents and publications in marine optics and marine robotics, and has been actively involved as Project Leader in the development of the Maya AUV and the autonomous vertical profiler. His current interest is in autonomous seabed systems for coastal oceanography.

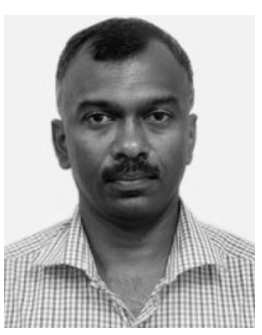

R. Madhan received the B.Tech. degree in electrical engineering from the Regional Engineering College, Calicut, Kerala, India, in 1990 and the M.Tech. degree in power and energy systems from the Regional Engineering College, Suratkal, Karnataka, India, in 1998.

Currently, he is Principal Scientist at the Marine Instrumentation Division, National Institute of Oceanography, Goa, India, having worked on the development of the Maya AUV, and the autonomous vertical profiler. He has publications and patents in the field of marine instrumentation and robotics. His interests are in the areas of mechanical design, power, and propulsion of marine robots.

Mr. Madhan was awarded the Partnership for Observation of the Global Oceans/Scientific Committee on Oceanic Research (POGO-SCOR) fellowship in 2007 and the National Research Development Corporation (NRDC) India Innovation Award for the autonomous vertical profiler in 2010.

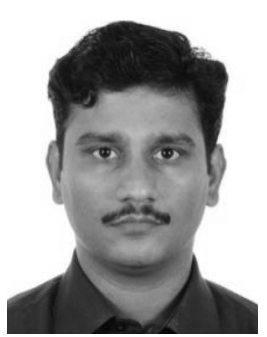

Nitin Dabholkar received the Graduation in electronics \& communication engineering degree from the Institution of Engineers, India, in 2006.

Currently, he is a Technical Assistant at the National Institute of Oceanography, Goa, India. During his tenure, he has worked on the development of the autonomous weather station and tide gauge. His interest includes software development and hardware design.

Mr. Dabholkar was awarded the meritorious invention award for the autonomous vertical profiler by the National Research Development Corporation (NRDC).

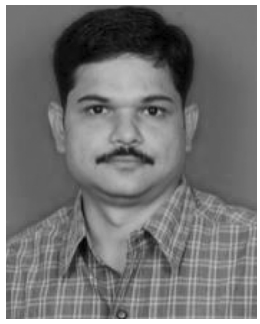

Shivanand Prabhudesai received the Diploma in mechanical engineering from the Government Polytechnic, Panjim, Goa, India, in 1993.

Currently, he is a Technical Officer at the Marine Instrumentation Division, National Institute of Oceanography, Goa, India, with mechanical contributions to making of Maya AUV and the present autonomous vertical profiler. His interests span computer-aided design (CAD), deep-water pressure systems, and autonomous technologies.

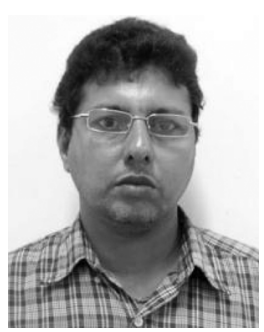

Gajanan Navelkar received the B.E. degree in electronics and telecommunications from the University of Bombay, Bombay, India, in 1986 and the M.Tech. degree in digital electronics from the Regional Engineering College, Surathkal, Karnataka, India, in 1998.

Currently, he is a Principal Scientist at the Marine Instrumentation Division, National Institute of Oceanography, Goa, India, and has worked on the development of Maya AUV and the autonomous vertical profiler (AVP).

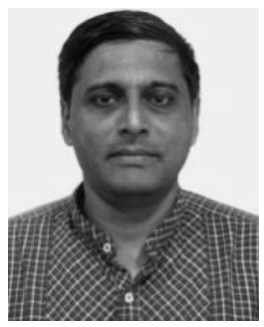

Antonio Mascarenhas received the B.E. degree in electronics and telecommunications and the M.E. degree in industrial engineering from the University of Bombay, Bombay, India, in 1986 and 1999, respectively.

Currently, he is a Senior Principal Scientist at the Marine Instrumentation Division, National Institute of Oceanography, Goa, India. He has worked on the development of Maya AUV, autonomous vertical profiler (AVP), and ocean color. His interests are in the areas of power systems, image processing, and ocean optics, and has publications in the field of marine robotics and ocean color. 


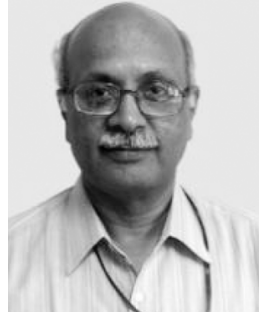

Sanjeev Afzulpurkar received the M.S. degree in applied electronics from the Osmania University, $\mathrm{Hy}$ derabad, Andra Pradesh, India, in 1981.

Currently, he is a Senior Principal Scientist in the Geological Oceanography Division, National Institute of Oceanography, Goa, India. His current interests are autonomous systems for oceanography, integration of acoustic systems for such platforms, and sensors. Additionally, he is involved in acquisition of ocean research vessel for the institute and field data acquisition systems.

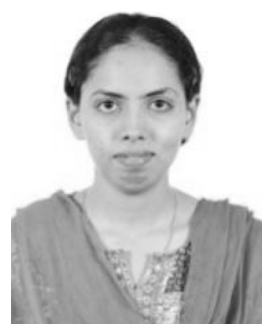

Mruga Phaldesai received the M.Sc. degree in electronics from Goa University, Goa, India, in 2007.

She was a Research Assistant in the Electronics Division, Goa University. Currently, she is a Project Assistant at the National Institute of Oceanography, Goa, India.

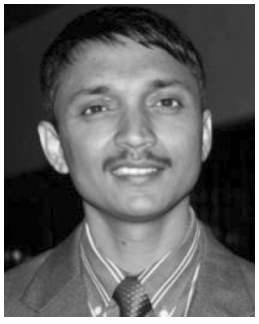

Pramod Kumar Maurya was born in Gorakhpur, India, in 1977. He received the M.S. degree in electronic science from Devi Ahilya University, Indore, Madhya Pradesh, India, in 1990. Currently, he is working toward the Ph.D. degree at the Instituto Superior Técnico (IST), Lisbon, Portugal.

He has worked as a Research Fellow at the Aeronautical Development Agency, Bangalore, India, for Light Combat Aircraft program of India. Currently, he is a Scientist at the Marine Instrumentation Division, National Institute of Oceanography, Goa, India. 